\title{
Max Meyerhof y su quehacer en la historia de la oftalmología del Medio Oriente
}

\section{Max Meyerhof and his contributions in the history of ophthalmology in the Middle East}

\author{
Rolando Neri-Vela ${ }^{1 *}$, Luis Sánchez-Fernández ${ }^{2}$ y Ericka X. Medina-González ${ }^{1}$ \\ ${ }^{1}$ Escuela Médico Naval, Comisión de Estudios Históricos Escuela Médico Militar, Ciudad de México, México; ${ }^{2}$ Facultad de Medicina, Universidad \\ de Oviedo, Asturias, España
}

\begin{abstract}
Resumen
Uno de los más grandes estudiosos de la historia de la oftalmología en el Medio Oriente fue Max Meyerhof, que entre sus grandes trabajos se dedicó a recopilar fuentes originales en los bazares de El Cairo y a aprender el árabe, rodeándose de hombres sabios, traduciendo esos antiguos escritos y dándolos a conocer al mundo occidental. Hacemos en este trabajo un recuento de su quehacer intelectual.
\end{abstract}

Palabras clave: Max Meyerhof. Oftalmología. Medio Oriente. Tracoma.

\begin{abstract}
One of the best academics in the history of ophthalmology in the Middle East was Max Meyerhof. One of his great contributions was collecting original papers in the bazaars in old Cairo, as well as learning Arabic, surrounding himself of scholars, translating those old manuscripts and introducing them to the West. In this work, we remember his intellectual contributions.
\end{abstract}

Key words: Max Meyerhof. Ophthalmology. Middle East. Trachoma.

En el siglo XIX se inició el interés por conocer la historia de la ciencia en el mundo árabe e islámico medieval y, así, uno de los más conocidos historiadores de la medicina islámica, Claudius F. Mayer, y otros pensadores decimonónicos europeos, como Sylvestre de Sacy, autor de la Anthologie grammaticale arabe, George W. Freytag, que escribió Lexicon AraboLatinum (1837), F. Wüstenfeld, que redactó Geschichte der arabischen Ärzte, Göttingen (1840), se dieron a la tarea de estudiar las raíces de esa historia, junto con Julius Theodore Zenker, quien compiló una bibliografía para arabistas, Gustav Flügel, R. Seligmann, el francés Lucian Leclerc, que publicó en París su Histoire de la médecine arabe en 1876, August Müller, editor del texto árabe de Ibn Asaibi'a' acerca de la biografía de los científicos de su época, escrita en el siglo XIII y que publicó en El Cairo en 1882, Edward W. Lane, reconocido por su traducción de Noches árabes y por

Correspondencia:

*Rolando Neri-Vela

Tuxpan, 16-401

Col. Roma

Fecha de recepción: 12-11-2019

C.P. 06760, Ciudad de México, México

E-mail: drnerivela @ hotmail.com

0187-4519/@ 2020 Sociedad Mexicana de Oftalmología. Publicado por Permanyer. Este es un artículo open access bajo la licencia CC BY-NC-ND (http://creativecommons.org/licenses/by-nc-nd/4.0/).
Fecha de aceptación: 17-05-2020

DOI: 10.24875/RMO.M2000012
Disponible en internet: 09-11-2020 Rev Mex Oftalmol. 2020;94(6):274-278

www.rmo.com.mx 
su Diccionario de la lengua árabe, Moritz Steinschneider, el gran erudito en la lengua semítica, cuyas publicaciones incluyen Die arabische Literatur der Juden (1902), y Brockelmann, cuya historia básica de la literatura árabe fue publicada al final del siglo (Geschichte der arabischen literatur, 1898-1902).

Desde que la afortunada expedición napoleónica llegó a Egipto en 1788, esta parte del planeta se convirtió en una atracción para los oculistas por su amplia difusión de las enfermedades de los ojos. Allí arribaron Tachau, que introdujo la oftalmología moderna y que fue llamado por los árabes iláh-el-‘ayín, el dios de los ojos, y Roberto Koch, en 1883, que había descubierto un año antes el bacilo de la tuberculosis, y que encontró el Vibrio cholera y la causa de la oftalmía egipcia. También Morax llegó desde París, así como Fuchs, Kuhnt y Julius Hirschberg, quien estuvo en aquellas tierras en $1889^{1}$.

Julius Hirschberg, eminente oftalmólogo e historiador de la oftalmología, junto con dos amigos orientalistas, Lippert y Mitwoch, pasaron una larga temporada recolectando, estudiando y traduciendo manuscritos árabes acerca de las enfermedades oculares para publicar en 1905 su trabajo acerca de la oftalmología árabe. Hirschberg y sus colaboradores abrieron una nueva veta de estudio en la historia de la ciencia árabe.

Una de las personalidades que contribuyó a esta rama del pensamiento humano fue Max Meyerhof (Fig. 1), nacido en Hildesheim el 21 de marzo de 1874 en el seno de una familia judía en la que se habían distinguido varios científicos y médicos. Su tío materno fue el Dr. Otto Spiegelberg, ginecólogo en Breslau y en Göttingen; dos de sus primos se hicieron famosos por sus estudios, el Dr. Wilhelm Spiegelberg, profesor de Egiptología en Estrasburgo, y el Dr. Otto Meyerhof, químico y fisiólogo, que trabajó sobre la química de las enzimas y fue galardonado con el Premio Nobel de Medicina en 1922.

Max Meyerhof estudió en Heidelberg y finalizó sus estudios en Estrasburgo hacia 1897. Fue entonces un approbierter Arzt, sin ser un doctor en medicina; para obtener su grado médico tendría que escribir una disertación doctoral.

En ese entonces, la bacteriología era aún una novedad, y Meyerhof se sintió atraído fuertemente por ella. Hizo una estancia de un año, en 1897, en el HygienischBakteriologisches Institut, de la Universidad de Estrasburgo, donde, bajo la tutoría de los profesores E. Levy y J. Forster, estudió la biología del Proteus, su patogenicidad y su resistencia al calor y se graduó en 1898.

Durante sus estudios de posgrado en Oftalmología recibió recordatorios constantes de que Egipto era un lugar importante para el estudio de las enfermedades

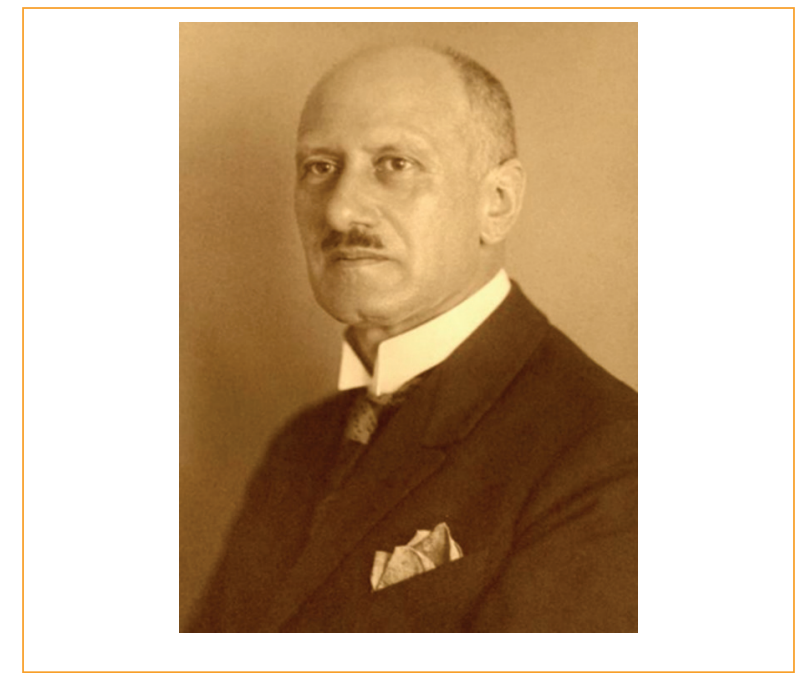

Figura 1. Max Meyerhof.

oculares: ya Tourtechot de Granger, que había publicado en París en 1745 su obra Relation du voyage fait en Egypte, había llamado al país «la tierra de los ciegos»².

Mientras Meyerhof estaba en Bromberg, fue invitado por su familia a acompañar a su primo Otto Meyerhof, a quien su médico le había recomendado visitar Egipto para recuperar completamente su salud, afectada por un padecimiento renal. En diciembre de 1900 llegó a Egipto, con mucha expectación, pues había mucho que ver y mucho de interés para un oftalmólogo en ciernes. A un lado de sus pirámides, la esfinge, los museos, las mezquitas de El Cairo y los recursos sanitarios de Assuan y Heluan, Meyerhof no podía ser de ayuda médica en esos momentos, pero se impresionó por el enorme número de ciegos, de tuertos y de débiles visuales que abundaban en las calles, en los bazares y en las escuelas, a todo lo largo y ancho del país.

Meyerhof, deseoso de visitar los hospitales oftalmológicos, investigó acerca de su situación, y para su sorpresa descubrió que no había ninguno, que las enfermedades oftalmológicas eran diagnosticadas incorrectamente, que el tracoma era confundido con la conjuntivitis primaveral y que no existía ninguna sociedad oftalmológica.

Tras su estancia en El Cairo retornó a Alemania, pero ya en octubre de 1903 regresó nuevamente a dicha ciudad llevando consigo cartas de recomendación para la comunidad alemana y para los directores germanos de varias instituciones médicas.

Mientras instalaba su consulta privada y ganaba experiencia sobre el folclor egipcio, Meyerhof consumía la mayor parte de su tiempo, antes de la Primera Guerra Mundial, en sus investigaciones oftalmológicas. 
Meyerhof fue presidente de la Sociedad Oftalmológica de Egipto en los años 1908 y $1909^{3}$.

Su primera relación con la historia de la medicina fue la búsqueda de manuscritos árabes no publicados en las librerías del barrio Khedive y en los alrededores de la mezquita de al-Azhar (Figs. 2 y 3), en 1905. Más tarde, sus visitas a las librerías de El Cairo se hicieron más frecuentes. La amistad con el sabio Ahmad Taimur Pasha y con los orientalistas de varios países hicieron de él un eminente historiador de la medicina árabe medieval $^{3}$.

El alza del nacionalismo fue benéfica, y bienvenida incluso, para los esfuerzos de organización de Meyerhof, pues, en sus demandas de 1905, los enunciados fueron esencialmente los mismos del lado médico que los de los nacionalistas en el aspecto político, a decir de Mayer: 1) campaña contra la superstición, el curanderismo y la indolencia de los nativos egipcios; 2) educación de los egipcios para la limpieza y mejor abastecimiento de agua; 3) distribución apropiada de médicos expertos en todo el país para el control del glaucoma y del tracoma, y 4) preparación de muchas salas de hospital para los enfermos de los ojos ${ }^{3}$.

En 1908, durante su presidencia de la Sociedad Oftalmológica de Egipto, pudo ver con alegría el nacimiento de un nuevo hospital en Tanta y que el parlamento egipcio contemplaba un presupuesto para la ampliación de los hospitales.

Durante los años de la Segunda Guerra Mundial, residiendo en Alemania, Meyerhof tuvo un consultorio en Hannover, pero pasó la mayor parte de su tiempo entre los estudiosos orientalistas. Fue el profesor Moritz, director de la biblioteca del Seminario Oriental en Berlín y a quien Meyerhof había conocido en 1905, cuando Moritz era director de la Biblioteca Khediva en El Cairo, quien animó a Meyerhof a buscar manuscritos oftalmológicos árabes. Hubo muchas otras personas que lo alentaron en esta tarea, como Eilhard Wiedemann y Stigler en Erlangen, Ernst Seidel en Meissen, Seligmann en Hamburgo, Horovitz en Frankfurt y Mittwoch, Georg Schweinfurth, Schäffer, Frank y Ruska en Berlín ${ }^{3}$.

Durante la segunda estancia de Max Meyerhof en Egipto, de 1923 a 1945, las oportunidades para la investigación oftalmológica se incrementaron: el gobierno egipcio decidió usar ciertos fondos derivados de la guerra para la construcción de un laboratorio oftalmológico y, después de algunos trámites, Meyerhof trabajó allí. Así, durante el día su quehacer transcurría en la oftalmología y sus horas libres las dedicaba por la noche al estudio de manuscritos árabes de medicina, botánica y farmacología, y, a partir de 1928, sobre

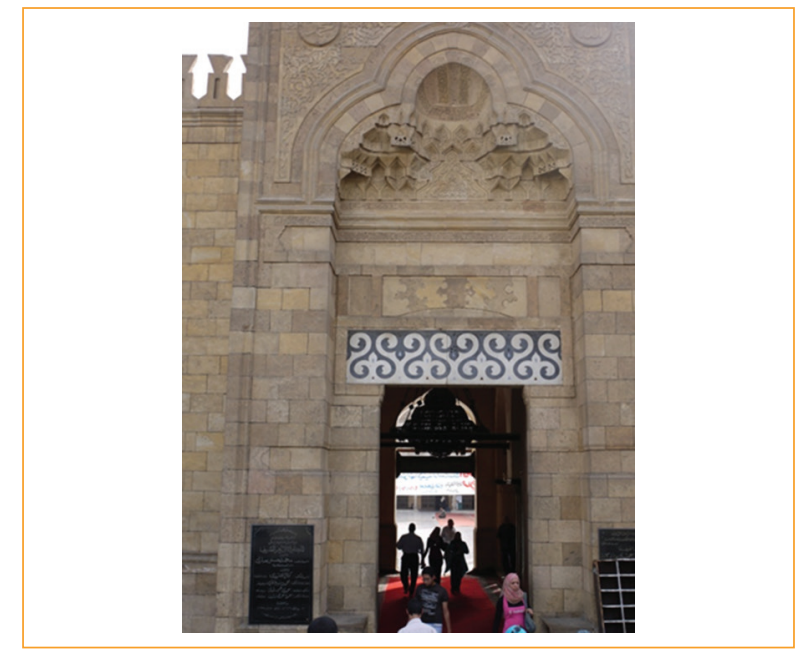

Figura 2. Mezquita de al-Azhar, El Cairo.



Figura 3. Mezquita de al-Azhar, El Cairo.

la vida de médicos judíos que habían practicado su arte en el mundo árabe en el Medievo.

El resultado de sus indagaciones fue una serie casi ininterrumpida de publicaciones. En 1928, la Universidad de Bonn le extendió un doctorado honorario, y en 1931 se convirtió en miembro honorario de la Royal Society of Medicine ${ }^{3}$.

Nuestro personaje fue un activo escritor durante cerca de 47 años, desde 1898, cuando publicó su disertación médica, hasta el momento de su muerte.

Meyerhof sintió que había cumplido con los requerimientos indicados por Julius Hirschberg para un historiador médico. Fue un experto en su especialidad médica y estudió la lengua árabe bajo la guía de $\mathrm{E}$. Littmann, sabio arabista, además de la ayuda y cooperación de sus amigos alemanes en Egipto. 
Desde 1905, cuando inició sus visitas a la Biblioteca Khedive, hoy Biblioteca Nacional de Egipto, y después de recorrer otras, como la de la vieja mezquita al-Azhar, contrató un copista árabe para transcribir cuanto material oftalmológico árabe encontrara ${ }^{3}$.

En una visita al droguero 'Abd-al-Magid, en un bazar en el que abundaban las hierbas, las semillas, el arsénico y las pinturas para los ojos, halló un manuscrito del siglo XV, de Dáúd al-Antáki, sobre las prescripciones de Kohen al-Attár para la composición exacta de la mezcla que las mujeres nubias deseaban usar para encontrar un encanto efectivo ${ }^{3}$.

En El Cairo, Meyerhof estuvo en contacto diariamente con la tradición centenaria, de una era olvidada en gran parte por el Oeste y que, sin embargo, aún seguía viva.

Cuando estalló la I Guerra Mundial, los intereses culturales de Meyerhof se habían ampliado. No solo se interesaba en las ramas de la medicina árabe y sus ciencias conexas, sino que también era consciente de la relación básica del Islam con las culturas grecorromana y bizantina.

Regresó de Alemania nuevamente en 1923, con una nueva ambición: redactar una historia de la medicina árabe basada en todas las fuentes originales disponibles.

Varios de sus artículos describen el conocimiento médico y farmacéutico de los egipcios, su comercio, sus bazares y el uso de narcóticos.

En sus estudios históricos y filológicos, la farmacología y la botánica reclamaron su interés y discutió el contenido de varios escritos farmacológicos de autores, como Idrisi, Ghafiqi, Biruni o Maimónides, y editó y tradujo frecuentemente a partir de manuscritos encontrados en la biblioteca. Analizó la influencia de Dioscórides sobre la farmacología árabe medieval y el ascendente de los árabes en el vocabulario de las drogas de España y Portugal. Muchos de sus escritos filológicos tienen origen en el deseo de corregir los diccionarios orientales disponibles, desvelar la etimología apropiada de los nombres de las drogas o trazar el significado exacto de algún término médico u oftalmológico ${ }^{3}$.

Otro tópico manejado por Meyerhof fue la historia egipcia de los siglos XVIII y XIX, de las enfermedades endémicas que se padecían en aquella región, en especial de aquellas reportadas por viajeros y médicos llegados allí y de las medidas adoptadas para el control de esas enfermedades. Describió la oftalmía que debilitó al ejército de Napoleón en 1798, el papel de los cirujanos británicos y de los médicos franceses en el desarrollo de varias instituciones para el control de las enfermedades oculares, la historia de la plaga de 1798 a 1802 en Egipto y las observaciones efectuadas por el Dr. Wolmar, un testigo y probablemente el primero en describir la leishmaniasis cutánea o «fiebre de Alepo». En la crónica de Jabarti (1754-1822) halló que la fiebre por dengue era conocida en Egipto desde 1799, mientras que la enciclopedia de Qalqasandi, del siglo XIV, mencionaba la enfermedad del sueño por primera vez. Meyerhof también estudió los primeros reportes impresos de los viajeros de las Indias Orientales, en el siglo XVII, sobre enfermedades tropicales ${ }^{3}$.

La actividad principal de Meyerhof fue la investigación analítica de la cultura árabe en el Medievo, y su restauración a partir de documentos originales no publicados. Sus méritos se pueden apreciar mejor mediante una revisión superficial de los manuscritos y publicaciones impresas de los autores árabes medievales que sirvieron a Meyerhof como fuentes en sus estudios históricos y como referencias en sus comentarios, del material que traducía o de los textos llevados a la imprenta. Sus fuentes manuscritas las reunió principalmente en las bibliotecas de El Cairo, pero muchas otras fueron enviadas a otros acervos de países islámicos o a Europa y América.

Uno de sus artículos más interesantes, a nuestro modo de ver, es A short history of ophthalmia during the Egyptian Campaigns of 1798-18074.

En este trabajo concluye, después de hacer una minuciosa descripción de las incursiones extranjeras en Egipto, que las descripciones realizadas de la oftalmía «egipcia» por los médicos militares eran vagas, excepto en el caso de una forma purulenta aguda identificada como conjuntivitis gonorreica. La descripción de las secuelas crónicas del padecimiento eran insuficientes y sin las imágenes de John Vetch de las granulaciones no hubiera sido posible decidir si se trataba 0 no de elementos tracomatosos. Añade que fue solo a partir de 1820 cuando descripciones más detalladas de la ophthalmia militaris seu Aegyptiaca se podían encontrar en la literatura, y que entonces se podía establecer que el genuino tracoma era una secuela frecuente de esta forma de conjuntivitis y que las formas de la "oftalmía egipcia» descritas por sus predecesores correspondían a una conjuntivitis catarral aguda, a una conjuntivitis purulenta aguda, a una conjuntivitis posgonorrea o a un genuino tracoma.

Max Meyerhof es, sin duda alguna, uno de los grandes oftalmólogos, tanto en el campo clínico-quirúrgico como en el histórico, que no pueden ser olvidados y 
que, como indicó en su tiempo el doctor Manuel Márquez, maestro en la Universidad Complutense y en el Instituto Politécnico Nacional en México: «El oftalmólogo debe ser, y lo es casi siempre, un estudiante perpetuo, y debe mantener su cultura oftalmológica además de su cultura médica general y de su cultura general no médica- a la altura de los progresos de la época en que vive» 5 .

\section{Bibliografía}

1. Mayer CF. Arabism, Egypt, and Max Meyerhof. Bull Hist Med. 1946;XIX(4):377-400.

2. MacCallan AF. The history of ophthalmology in Egypt. Br J Ophthalmol. 1927;11(12):602-9.

3. Gorin G. History of ophthalmology. Wilmington, Delawere: Publish or Perish, Inc.; 1982. p. 273.

4. Meyerhof M. A short history of ophthalmia during the Egyptian campaigns of 1798-1807. Br J Ophthalmol. 1932;16(3):129-52.

5. Márquez M. Oftalmología especial teórica y práctica. México: La Prensa Médica Mexicana; 1952. 